\title{
Understanding the Importance, Impacts and Barriers of ICT on Teaching and Learning in East African Countries
}

\author{
Berhane Aradom Tedla \\ Northeast Normal University
}

\begin{abstract}
This paper based on synthesis of the research literature, observation and focused group discussion with East African Scholars on the use of Information and Computer Technology (ICT) in primary and secondary schools in East African Countries with a particular focus to understand the importance, impacts and barriers of ICT into classroom Instruction. The study explored internal and external factors that surround ICT issues, policies of ICT integration and factors that facilitate or impede the use of ICT, with the focus of improving the quality of teaching-learning process. The study reveals that the inhibiting factors are unrealistic policies of ICT, poor infrastructure, lack of teacher competence, confidence, incentive, perception and beliefs, imposed curriculum, lack of proper network, political instability, brain drain, sporadic electricity, poor transportation, lack of public awareness and participation, poor school leadership, technological illiteracy and lack of pedagogical skills. The study further revealed that ICT integration is far behind in East African Schools as a consequence of ICT deficiency, absence of pre-service and in-service teacher training and poor teachers' welfare and morale. Eventually, the study concluded that ICT is crucial for anytime and anyplace learning to ensure economic growth and it highlighted the important issues for consideration and improvements.
\end{abstract}

\section{Introduction}

The rapid global technological advancement and economic development places a great investment into education. Nowadays, with the expansion of knowledge, advancement of technology as well as globalization issues, the profession 'teaching' becomes a central figure and most challenging, for it requires new planning and technological adaptation to cope with cultural dynamism. Teachers are implementers, and thus need to learn and apply new technologies into their classroom instructions. Governments in East African countries as elsewhere, are more conscious more than ever about the importance of ICT in the development of a nation in several aspects, such as educational development, economic growth, social awareness, cultural enrichment and political leadership. The use of ICT in schools is crucial for the development of economic and social change worldwide $[1,2]$. Similarly, ICT plays a major role in the developing countries to go through economic, political, social and cultural development [3]. This implies that ICT has a profound impact on how teachers teach and students learn, and how people live, business and communicate in the day to day activities. It provides opportunities to stimulate learning and increase motivation that enables teachers and students to interact productively with neighboring communities and global economy in a wider and higher scope. To realize this opportunity, however, technologies need to be part of the curricula. The effort becomes more fruitful, achievable and down to earth for practice, if it's combined with the efforts and initiatives of local leaders, educators and entrepreneurs. In other words, ICT has tremendous potential to change the way of life, prepare students for the workplaces, improvement of educational systems and attainment along with how people access and process information, if it's integrated wisely into a curriculum by the collaborating with interested individuals. Ultimately, the formation and application of ICT into classroom instruction embedded in the mission of the East African Countries. This calls a solid and well established national strategy and policy on ICT integration into classroom instructions. In the study, it was reviewed that the selected countries has a national policy that promotes the use and integration of ICT into schools, and in turn produces a quality education.

There is substantial evidence that Information and Communication Technology promote a quality education and effective teaching- learning atmosphere for both a student and teacher. Several research studies indicate that Information and communication technology (ICT) provides educational opportunities and environmental readiness for classroom instruction. More essentially, ICT plays a greater role in generating of knowledge and processing information for problem solving and further exploration. However, it remains to be seen how teachers use, integrate and invite students 
to learn, access, gather, process, analyze, transmit and simulate information. The usage of ICT into classroom instruction is a more practical, interactive and innovative aspect rather than theoretical. In effect, the impact of ICT on education is one of the most critical issues [4]. It's powerful instrument that enables practical environment and assists new ways of teaching and learning, and helps students to develop knowledge and skills for cooperation, communication and problem solving. The use of ICT into classrooms instruction, however, remains as a sole role of teachers [5].

In many African Countries, particularly in East Africa, most teachers do not integrate ICT into their instruction as it should be, because of several interrelated factors, such as manipulative, nonmanipulative and teacher factors. Manipulative factors include beliefs, skills and commitment of teachers, ICT knowledge, availability of ICT resources, whereas nonmanipulative factors include age, gender, religion, educational experience, computer experience, national policy and external supports. This implies that ICT integration is not dependent on one factor, but to several interrelated factors that directly or indirectly affect the use of ICT into classroom instructions.

Availability of ICT resources does not guarantee effective implementation without teachers' good conditions and pedagogical expertise. A continuous teachers' professional development on the use of ICT is far important as a tool for enhancing an effective instruction. Hence, it is the work of concerned bodies like policy makers and trainers from ministry of education to understand and identify the factors that affect teachers on the use of ICT and to provide a training ground for ICT use. Recently, in East African Countries, there is an increasing awareness about the importance of ICT to enhance educational standards, but its practical application remains a critical issue, because of some major problems, such as broken and collapsed economy, lack of qualified teachers, inadequacy of teachers' funding for salary, poor working conditions, HIV/AIDS, high student enrollment and the failure of experts to integrate ICT into curricula. The review reveals that the countries in the study have played a critical role to incorporate and progress ICT into schools as part of their curricula with the exception of Somalia. These findings backed by the participants that these countries have clearly established policies and strategies about the use of ICT into schools. The policies are wide enough and tend to highlight an enriched curriculum with ICT and teacher development. This is a sign of awareness to provide technological equipments that enable educational change, raise educational standard, teacher skills and pedagogical knowledge. The increased investment into education by governments has led further elaboration of policy and strategy on ICT integration into schools.
The infrastructure and availability of data, however, remains outdated and scarce, especially in poor rural areas. The integration of ICT into primary schools is negligible except in Tanzania and; more emphasis is given on secondary schools. The policies are more ambitious and promising, but they lack the corresponding technological equipments. In meeting such limitation, nowadays, schools start to initiate partnership with domestic and foreign agents as sources of ICT materials.

\section{Objective of the Study}

- To explore the importance, impacts and barriers of ICT integration into classroom instruction

- $\quad$ To explore and examine issues about policies and teacher factors related to ICT, such as pedagogical expertise, perception, competence, confidence, availability of ICT resources and the other factors.

- $\quad$ To explore the nature of ICT in East African Countries and how teachers integrate/use ICT, why they use it and what factors are preventing teachers from integrating ICT into classroom instruction.

\subsection{Research Questions and Methodology}

\section{Key Questions:}

- What are the importance and impacts of ICT?

- What's the status of ICT integration in East African Countries?

- What policies are at hands for ICT usage?

- What are the inhibiting factors?

\section{Methodology}

In exploring these research questions, the researcher employs observation, empirical literature reviews and focused group discussion with East African Scholars. The researcher reviews substantial empirical researches in African Context, especially in East African Countries with the exception of Somalia. The researcher, however, discovered that most of researches highlight detrimental effect of poverty and political instability in the regions as a main dilemma of ICT integration. There are no much researches about teachers' welfare, morale, confidence, competency, partnership and public awareness. In case of observation, the researcher was privileged to observe 
different schools at different levels in different times since undergraduate study as a student, teacher and researcher, for almost seven years.

\subsection{Scope, Limitation and Significance}

This paper includes all types of hardware and software technologies relating to ICT, but does not cover all East African Countries. It is limited to Eritrea, Ethiopia, Tanzania, Kenya, Uganda, and Somalia. Though it's limited in scope, it unveiled important facts and will serve as a base for further research. The study employed observation, focused group discussion and synthesis of related research literatures as a method of data collection. The focused group discussion was conducted with East African Scholars who study their postgraduate studies at Northeast Normal University, china. The study, however, did not cover key stakeholders and agents, such as national policy makers, strategists, curriculum developers, school leaders, academician, parents and community members who may play a significant role to integrate and change ICT. In the discussion, the researcher, tried to focus and identify policies, practices, impacts, challenges, barriers, and outcome ICT integration. The discussants shared their experiences as teachers and students about the issue ICT integration and implementation.

Table 1 indicates the profile of participants in the group discussion

Table 1. The profile of participants in the focused group discussion

\begin{tabular}{|c|l|c|l|l|}
\hline$\#$ & Country & $\begin{array}{l}\text { \# of } \\
\text { informants }\end{array}$ & Age & $\begin{array}{l}\text { Year of } \\
\text { teaching } \\
\text { experience }\end{array}$ \\
\hline 1 & Eritrea & 7 & $27-35$ & $3-11$ years \\
\hline 2 & Ethiopia & 9 & $26-36$ & $4-9$ years \\
\hline 3 & Kenya & 2 & $31-40$ & $5-7$ years \\
\hline 4 & Somalia & 1 & 28 & 4 years \\
\hline 5 & Tanzania & 9 & $25-32$ & $6-8$ years \\
\hline 6 & Uganda & 3 & $28-34$ & $3-9$ years \\
\hline \multicolumn{2}{|l}{ Total } & 31 & & \\
\hline
\end{tabular}

\section{Literature Review and Focused Group Discussion}

\subsection{Importance of ICT into classroom instruction}

Several studies from case studies to survey researches have been conducted about the importance of ICT and as why teachers use it. They reveal that the use of ICT is inherently advantageous to support, facilitate and make easier teaching-learning process. As of this importance, research results highlight professional development in the area, supportive models, visionary policy and pedagogical expertise.

ICT comprises several multimedia tools, such as computers, broadcasting technologies (radio and television), the internet, telephone and the like. Nevertheless, computer more than ever has caught the attention of the world-web-community because of its very nature to process, store and retrieve information, and helps students and teachers to facilitate and handle complex problems. The use of ICT, particularly a computer stimulates a new atmosphere where teachers and students could interact and collaborate to learn new skills of understanding about any subject matter and solving complex problems. In order ICT to stimulate a learning environment, however, the objective needs to be specific and achievable. ICT has three objectives in education: ICT as an object of study, discipline organization and medium of teaching and learning [6]. Therefore, ICT is an important for students to develop cognitive skills in their daily lives, professionals to organize disciplines and as a medium to promote conducive learning atmosphere among teachers and students. Similarly the innovative use of ICT can promote student-centre learning [7]. Hence, teachers need to use ICT to enhance student learning, for it helps students to engage in problem solving, decision making reasoning [8]. This implies that ICT is important for fast and easy learning to process, store and retrieve information, and as a result students develop cognitive skills and behaviors to solve problems. In the focused group discussion, it was revealed that the importance of ICT is beyond measure to quantify. The influential factors of ICT were discusses, debated and eventually analyzed. It was reported that teacher attitude is one of the most critical factors that enhance or inhibit the integration of ICT into classroom instruction. Teacher attitude and competence ensure ICT implementation and guarantee further ICT innovation. They also help to promote approaches, standards and harmonization of ICT tasks, the awareness ICT equity, utilization and maintenance of ICT, implementation of ICT training, assessment and evaluation, development of ICT, dissemination of pedagogical knowledge, professional development, etc.

The findings from the focused group discussion indicate that the importance of ICT is far beyond measure. The informants reported that ICT makes a classroom a playfield where teachers and students interact, communicate and collaborate during the time of instruction. Some discussed that in the absence of ICT, some students count time to dismiss the instruction, whereas in the presence of ICT students want to stay and buy more time. One unique 
respondent reported that the absence of ICT during instruction was giving me hard time, for it required me a lot of energy and time to explain things until all the students understand; on the contrary, in the presence of ICT, respondent added, my instruction was a fun with high participation and deep understanding. Furthermore, the respondent explained that my school lacks all the necessary ICT tools. As a consequence, I used to borrow Laptop and other multimedia tools from the city. In line with this, the participants commented that teachers in East Africa need to be cognizant about the importance of ICT and make an endeavor to get ICT materials by their own, if the schools fail to provide. Furthermore they commented that concerned bodies need to offer a continuous professional training for teachers on the use of ICT and provide ICT materials.

\subsection{ICT Integration by teachers}

Normally, ICT is not part of a curriculum; like any other discipline it's a separate subject. Because of this, realistic policies are very important for its integration. Hence, it can be taken ICT as a subject (separated) and ICT in subjects (integrated). ICT policies need to be formulated and planned to complement and support curricula with technologies infrastructures. Nowadays, in the era of tough competition, nations could not longer depend on traditional approach and stand anymore globalization issues without ICT integration. Strangely enough, none of the sample countries have done a comprehensive pilot study before ICT policy establishment. They have a policy on ICT integration, but it's doesn't reflect the reality and cannot be transformed into an action without exploring the true ground and synthesis of expertise and experiences from other countries. In the focused group discussion, it was discovered that some African Countries borrow foreign countries ideas and experiences, and instantly adapt as part of their experiences while some synthesize expertise and experiences and integrate to their own philosophies. Borrowed policies on ICT issue always remain impractical and bound to fail. Realistic policy serves as a framework, blueprint or roadmap to integrate and facilitate ICT implementation in schools. This is a call for East African Countries to learn from their experiences and exploit their potential resources (human \& material). Most importantly, teachers need to play their highest roles and produce models towards technology application in their teaching profession.

It is true that teachers are changing agents for teaching and learning to occur. Their role as teachers has a far reaching effect to a school performance. Teachers are at the center of curricular changes and control the teaching-learning process [6]. Hence, teachers should prepare students for the knowledge society in order to acquire the competency of ICT use to process information. Effective application of ICT into classroom heavily relies on the availability of technological resources, qualified and confident teacher and other internal and external factors that directly or indirectly affect teachers' welfare and morale. In this regard, technological tools assist teachers need for the visions of technological potential, opportunities to use and training to experiment [9]. Similarly, ICT can change the way teachers teach, particularly in student-centered approaches for developing collaboration and the highest skills [10]. However, there is a clear cut difference between teachers who use ICT to facilitate learning for understanding a particular topic and those who use resource only for presenting the topic without direct application [11]. First teachers employ the pedagogical expertise and maximize the use of ICT for students' achievements. However, the focused group discussion with scholars from East Africa clearly indicated that teachers in East African are not competent enough to integrate ICT into classrooms. ICT competency standard has three things: technological literacy, deep knowledge and knowledge creation [12]. Similarly, some researches indicated that several school leaders perceive that the lack of ICT related to knowledge is a major challenge to the realization of ICT [13].

Several studies reveal that teacher's characteristics play a greater role on the use of ICT. Teacher characteristics refer to the educational level, teaching and computer experiences, age, gender, and financial position. A study by the National Center for Educational Statistics (2000) reported that teachers with fewer years of teaching experiences use computers than teachers of longer teaching experience. The report quantified it this way: teachers with three or less teaching experience use computers $48 \%$ of their time, four to nine years of experience use $45 \%$ of their time, ten to nineteen years of teaching experience use $47 \%$ of their time and teachers with more than 20 years of teaching experience use computers only $33 \%$ of their time[14]. The researcher discussed these finding with the focused group discussion of East African scholars. Some indicated that it could be due to age; while some reported that due to one's belief background. They further reported that old teachers are technophobic towards the use of computers and some teachers because of their beliefs system consider the use of computer as a sin.

Most of informants in the group discussion stated that they have never taken training on ICT usage. This implies that teachers require ICT training both at preservice and in-service levels. Teachers can be trained on how to use ICT and ICT is important as a means of training process [15]. They further reported that teachers have a positive perception on the use of ICT, 
but the availability and accessibility of ICT resources, such as hardware, software and communication infrastructure are limited. If there are some ICT resources in a school, they are only limited to an office use. One informant reported that in East Africa, let alone ICT resources, even some schools in the rural areas they don't have adequate chairs, blackboards and pure water, and besides teachers' welfare and morale is also very low. As a consequence, teachers are searching part time jobs to lift their well being particularly from Somalia, Eritrea and Ethiopia, and some also migrate to western countries to improve their lives.

\subsection{Factors preventing the use of ICT}

There are several factors that inhibit the application of ICT into classroom instruction. Some factors are school base (internal) while some are community base (external) and teacher's personal issue. The impact factor could be different, but these factors affect the use of ICT directly or indirectly in a great way. Researches identify these factors as non-manipulative, manipulative and teacher factors. Non-manipulative refers to the factors, such as age, teaching experience, computer experience, government policy and the availability of external support; whereas the manipulative factors refers to teachers' attitude towards the use of ICT, teachers' knowledge and skills about ICT, and school commitment for implementation process[16].

The discussion with the focused group reveals that in East Africa, there is a lack of a practical policy on ICT integration into curricula. This affects negatively the application and provision of ICT, and teachers' confidence and competence. In addition to this, East African Countries suffer the inadequacy of technological infrastructure, such as hardware, software, limited internet access, poor bandwidth, sporadic electricity, lack of pure water, political conflict, geographical factors, such as country size, mountains, demographic factors, such as high population, increased density, and extreme poverty, HIV/AIDS, lack of teachers' participation in curriculum development and evaluation, lack of preservice and in-service training, teachers' brain drain to the western countries, poor teachers' welfare and morale, lack of parent and community participation in schools, poor school vision, mission and leadership. In the discussion, a participant explained that problems or inhibiting factors could be avoided but some can be reduced. Some are natural while some are school failures. The greatest problems I have ever met during my teaching career, however, was not lack of ICT access, lack of expertise or awareness, but absence of incentive, lack of adequate time and rigid policy. In addition to this, some participants indicated the existing the curricula are more content wise that do not leave a time to integrate and innovate ICT. ICT integration is merely left to teachers; school principals and administrators are less supportive and encouraging. Nowadays, there is a high public awareness about ICT integration. This places a high pressure to teachers for its implementation, but the support and incentive from public and school leadership to teachers is very limited. A unique participant explained that a teacher is a victim of high public expectations and unrealistic policies. It's a mandatory policy that school should integrate ICT across their curricula and teachers are the immediate subjects to carry the pressure and show their schemes of work to incorporate ICT.

Availability of ICT is principal thing and then teacher awareness and competence. In the focused group discussion, however, discovered that there is a common misconception in the public that availability of ICT materials in schools is enough by itself. ICT materials don't guarantee integration unless the right condition, attitude and expertise are in place. The findings from the focused group discussion indicate that the use of ICT is highly dependent on the personal characteristics of a teacher, particularly teacher's competency, perception and age. Young teachers relatively had a greater opportunity to be trained in ICT classroom than old teachers, because the importance of ICT became apparent during years of 90's. This dramatically influences the teachers' perception towards the use of ICT into classroom instructions. The informants further explained that teacher's characteristics, such as teaching experience in the areas also dependent on the availability of professional training of ICT, availability of ICT materials in a school, parent and community thrust and involvement, school leadership and policy issues. In line with this, it's partly indicated that if vision on the use of ICT is successfully created, then the next step will be to articulate the integration of ICT to teachers [17]. ICT vision is important to effective ICT integration [18]. Similarly, when parents are encouraged to participate and contribute into school's ICT plan, change will likely come promptly [19]. Therefore, lacks of clear vision on ICT use and parent involvement impede the integration of ICT use into classroom instruction.

Apart from this, the focused group discussion further reveals that most East African schools, particularly in rural areas greatly suffer the lack basic school materials, such as chairs, proper blackboards, pure water and electricity. Some students in the case of Somalia sit on the floor. Most schools in the rural areas don't have ICT materials; may be one computer for report writing, data processing and other office tasks. This may be attributed to poor regional transportation, 
weak institutional capacity, ICT network gap, energy deficit, unrealistic policy, financial crisis, political instability, lack of privation sectors, highly centralized educational system, and the like. Another big challenge, but also a potential opportunity is unwisely exploited natural resources.

\section{Discussion and Conclusion}

Bringing ICT into practice has a major impact to facilitate and improve learning. In the study, it was discovered that Eastern African countries have a policies and strategies that promote ICT integration into a curriculum, dissemination of knowledge, development of e-learning, distance education, resource mobilization, development of teacher professionalism, skilled personnel and create an awareness of ICT for establishment ICT centers. Policies highlight the integration of ICT into a curriculum and teacher training development as a central figure in East African countries. The policy, however, is too ambitious and little bit impractical, for it fails to integrate the existing instructional resources with newly introduced, produce skilled personnel, increase a widespread awareness and build up the necessary infrastructures. The policy is indeed very promising, but because of the lack of pre-service and in-service training of teachers its adoption and implementation become very problematic and remains as a mere policy. ICT into schools is not only a matter of policy, but of vision and strategy. Policy, vision and strategy broaden environmental ICT context, facilitate Technological infrastructure, promote professional development, improves curriculum, pedagogy and content enrichment, management and finance utilization and easy monitoring and evaluation. During the focused group discussion, the participants claim that before policy implementation and introducing of infrastructure facilities, teacher awareness and competence need to be flourished and enhanced. Teacher professional development in the area assists to increase teachers' confidence and competence. The study shows that teachers who use ICT wisely possess the competencies, positive attitude and skills. However, they stressed, "It's hard to change teachers' beliefs. Some teachers are indifferent while some are technophobic to the use of ICT into their classroom instruction. Some of these attributes to religious reasons and some are due to age and lack awareness. Higher the age, the greater the resistance becomes. Young teachers tend to be friendlier with technological materials for usage in their classrooms', The discussants highlight the importance of buddy team in a school that would help technophobic teachers to change their mindset and novice teachers to learn and experience faster. Some also highlight the importance of incentives and supports to teachers to use ICT as a motivational strategy. During observation time, the researcher learned that action research is one of the best ways to boost teachers' spirit, competence and confidence. In many schools, however, action research is still unknown. Otherwise, action research helps teachers to become part of ICT integration and most importantly it helps as an evaluation methodology.

Information and communication technology (ICT) creates a room to explore new things, provides a conducive climate for teaching-learning process to take place, and it also offers teachers the opportunity to play flexibility and enjoy effective ways of communication, collaboration, processing and solving of complex problems. This in turn, provides students the condition to develop their cognitive skills. The integration of ICT into classroom instructions, however, remains far behind because of several inhibiting factors, such as the inadequacy of infrastructures (internet access, bandwidth, software, hardware, computers), lack of realistic policy on ICT use, lack of teacher's preservice and in-service training, poor teachers' welfare and morale, lack of parent and community participation, political and social conflict, and tribal upheavals. Furthermore, it's discovered that the importance of empirical research on the use of ICT is imperative in order to expose further inhibiting factors and in the meantime to promote training opportunities that are crucial towards learning process, teacher satisfaction and student achievement. The wise use of ICT, however, broadens teacher horizons, study and teaching flexibility, endorses wide access of learning and student participation and sensible opportunity when and how to use ICT.

The synthesis of research literatures and discussion with the focused group further reveal that the importance of ICT integration is far beyond to measure and indispensable for effective cross-curricular student learning and teacher global community. ICT integration should be cross-curricular rather than focused to one subject [20]. Similarly, ICT should be used to serve educational objectives for skill development, assessing information, cooperation, communication and problem solving [21].

From study, it can be deduced that the benefits of ICT in a more tangible manner, among which the following are worth to mention:

- Generating of information and ideas

- Fast information processing, analyzing and problem solving

- High student management

- Increased teacher and student motivation

- Enhanced subject matter mastery by teachers

- High student interaction with the content

- Enhanced confidence and high self esteem

- Self directed and independent learning 
- High quality output

- $\quad$ Reduced teaching load

- Accommodation of new technologies with the existing ICT materials

- Integration of content into projects

- Easy teacher, student and content evaluation

- Easier communication across units and better collaboration among stakeholders.

Integration of ICT into classroom instructions helps teachers to extend and explore their subject area, plan and prepare an effective lessons, enhancing their pedagogical expertise, adapt with the expansion of technology, increase their competence, skills and confidence, change their beliefs, make teaching a fun, promote digital education, stimulate student learning, generate fast information, build a body of knowledge and computer experience. In the study, however, some pitfalls or difficulties are identified, from which the following are most noticeable:

- Students become off task

- Poor planning and preparation

- Unrealistic ICT policies

- Overloaded teaching tasks

- Old instructional practices

- Low teacher welfare and moral

- Poor infrastructural facilities

- Low community participation and involvement

- Leaving ICT integration responsibility to teachers

- Alien school leadership to ICT

- Negative teacher beliefs

- Lack of pre-and in-service trainings

- Low bandwidth

- Inequitable ICT distribution

- Lack of school base management

- Less partnership among schools

- Sporadic source of electricity

- Lack of incentives and support

- Unchanged pedagogy

- Imposed curricula

The most problematic issue to ICT integration is, however, the traditional or old fashioned way of transmitting knowledge students. This approach assumes that students better learn through teacher explanation and active listeners. This kind of approach took a deep root into school practices that it becomes hard to change the mind of those who have been trained in this approach. As a consequence of this, nowadays, it becomes a problematic to change the attitude of teachers and install ICT programs into classroom instructions. Often times, it's hard to break old habits and adapt to new technological innovations. This approach, however, the most prevailing method of teaching in developing countries, particularly in East
African Countries. Students assume considerable interaction in constructivist approach than in traditional, for it relates to their daily experience and more concrete in learning. Although, there are countless inhibiting factors, changing old habits or breaking old practices is the most critical issue. In the study, it was revealed that schools still comfortable with the old teaching methodology and it's also reasonable to be as such, for they lack the basic materials, such as chairs, pure water, electricity and proper blackboard. A unique participant explained that it's a irrational to expect schools to adapt ICT materials into classroom instructions with all these detrimental conditions. Hence, without sweeping infrastructural changes, ICT integration will remain unrealized dream. Here the role of teacher is critical to alleviate the detrimental conditions, for teachers are the immediate agents of change and innovation as well as victims of public expectation. Other inhibiting factors are lack teachers' readiness, inaccessibility of ICT resources, but poor teacher welfare and lack of pre-service and inservice training on ICT.

ICT in education falls under a broader contexts educational arena, economical sectors, social infrastructures, cultural context and global market. This means that ICT with clear vision, policy and strategy becomes part and parcel of every life sector, and because of its very nature it enables teachers to make their instructions more realistic, observable and achievable. In conclusion, the researcher calls inclusive, realistic, holistic and comprehensive policy across East African Countries that can enhance infrastructure, sustainable ICT integration, teachers' professional development and computer skills. In this matter, school leadership is a principal driver for ICT implementation through strategic human investment, collaboration, partnership and educational change. Wisely integrated ICT into a curriculum harnesses further educational, political, economical, social and cultural developments. This outcome, however, will happen into reality as byproduct of public awareness and teachers' personal attitude, competence and confidence. Public awareness thrusts huge investment to schools that in turn will help schools to build the necessary infrastructures and distribute access evenly. Policy is not enough by itself unless teachers understand the importance and impact of ICT in all areas, such as students' intellectual capacity, economic expansion, political solidarity and social fiber developments. This requires teachers to use constructivism approach rather than traditional. Constructivism approach by its very nature is a more practical and experience built. Hence, wisely integrated ICT into a constructivism curriculum provides the right condition for deeper understanding, independent learning and self-motivate task. One unique participant 
in the discussion put it forward this way: the era of ICT changes the way of learning from helpless to selfmotivated and independent learning. Students, nowadays, go extra miles beyond lessons to explore and generate huge information. In effect, some students from well-to-do family are highly informed and techno addicted more than teachers. Wisely integrate ICT into a curriculum:

- $\quad$ Promote anytime and anyplace learning

- $\quad$ Expand the pool of teachers and students

- Reduce education cost

- Speed up economic growth

- Helps cope with globalization issues

- $\quad$ Fast and wide networks

\section{Recommendation and Practice for Application}

Based on the findings, the researcher came up with the following recommendation and practices for application:

\subsection{Recommendation to policy makers}

Information and communication technology plays significant role in a development of a society and society's adaptation to global technological expansion. Consider that all students walk through primary to tertiary education, and thus ICT need to be incorporated to facilitate the walk of learning and discovery of new ideas. In this respect, a school places an appropriate and crucial role to make sure that the right conditions and instructional materials are on place. Hence, policy maker should target and integrate ICT into a curriculum with an account of economic, cultural, political, social, educational and catalytic rationales. In nutshell, they should:

- $\quad$ Prepare ICT master plan development

- Develop ICT networks not only in schools, but also among schools within a particular country

- Develop broad ICT integrated curriculum at all levels of education

- Encourage and pave the path for schools to participate in global ICT issues

- Campaign a public awareness to have high level of parents and community involvement.

Schools, families and communities should work abreast with the ministry of education in order to locate ICT availability and plant to schools accordingly.
ICT can bring a lot of changes in several areas in East African Countries. Therefore, teacher trainers and policy makers should provide professional development and understand the inhibiting factors of ICT integration

\subsection{Recommendation to Schools}

Application of ICT into education has unquestionable importance to the enhancement of productivity, quality education and new skill. ICT is a prominent tool to generate new information and processing, and handling of knowledge. As ICT is evolving always, young generations need to learn the subsequent innovations. Therefore, schools should be competent enough to enhance the transmission of information with new skills to their beneficial.

Presently, school improvement and effectiveness is a highlight in several literatures. Schools endeavor to enhance progress and bring academic excellence. As of this, ICT integration into a curriculum becomes a primary focus and center of debate about its importance and impact. School leaders and teachers are awareness enough about the importance of ICT as a catalyst to facilitate teaching-learning process. However, ICT integration still remains impractical and open issue. Hence, schools should change the role of a teacher from traditional to constructivism approach, and should promote high monitoring, evaluation, and new planning approach.

\subsection{Recommendation to Communities}

ICT integration and implementation is not only the function of policy makers and teachers. The best practice requires the efforts concerned bodies and every individual in the field. Hence, schools, policy makers and governments should encourage strong collaboration among schools and regional countries and work toward gaining the input of the many and should review also the past events collaboratively so as to progress effectively.

\subsection{Recommendation to Government}

Generally speaking, African Countries have plenty of natural resources, but it still remained unused or exploited wrongly by their poor leadership. The challenge is high; however the opportunity is much higher. As poverty is limiting the ICT integration and implementation, governments should learn to exploit and distribute evenly the abundant natural resources, minerals, solar and hydropower sources wisely. 


\subsection{Recommendation to Teachers}

Teachers are the changing agents, explorers of classroom instruction and key ICT integrators. Therefore, teachers' welfare and morale should be improved in order to bring commitment and stop brain drain towards western countries. In the mean time, teachers also should ask themselves following probing questions as a way of ICT incorporation:

- What is learned and how it's transmitted?

- When and where ICT is important

- Who is learning and teaching

- What good practices exists and how they're used to move forward

\section{References}

[1] J. Leach. Do New Information and Communication Technologies Have a Role to Play In the Achievement of Education For All? British Educational Research Journal. 34(6), 783-805. 2008.

[2]R.B. Kozma. National policy that connect ICT-based education reform to economic and social development. An Interdisciplinary Journal on Humans in ICT Environment.1(2), 117-156. 2005.

[3]A. Kelles-Viitanen. The Role of ICT in Poverty Reduction. 82-94

[4] C, Webber. Introduction New Technology and Educative leadership. Journal of educational administration. 2003.41(2)

[5] J. Voogt. Consequences of ICT for aims, contents, process and environmental of learning. U.Hameyer(eds). Curriculum landscapes and Trends. Dordecht: Kluwer. 2003

[6] TJ. Plomp A.C.A. Ten Brummelhis and R. Rapmund. Teaching and learning for the future. Report of the committee on multimedia and teacher training. Den Haag: SDU. 1996

[7] M. Drent. On the road to innovative use of ICT in teacher education. Doctoral dissertation. Enschede: University of Twente. 2005.

[8] M. Grabe and C. Grabe. Integrating technology for meaningful learning. Houghton Muffin Company. USA. 2001

[9] J. Bowes. The emerging repertoire demanded of teachers of the future: surviving the transition, from http://crpit.com/confpapers/CRPITV23Bowes.pdf, retrieved on July 24, 2011

[10] W.D. Haddad. Is instructional technology a must for learning? Techknowlogi.org, from

http://www.techknowlogia.org/TKL_active_pages2/CurrentA rticles/main.asp?IssueNumber=19\&FileType=HTML\&Articl eID=455, retrieved on August 13, 2011
[11] M. Cox, W.Aboot, C.Blakeley, T.B. Beauchamp and V. Rhodes. ICT and pedagogy: a review of the research literature. Department for education and skills. London. 2003

[12] UNESCO. ICT competency standards for teachers: implementation guidelines, version 1 , from http://cst.unescoci.org/sites/projects/cst/default.aspx, retrieved on July 11, 2011.

[13] W.J. Pelgrum. The effectiveness of ICT in schools: current trends and future prospects discussion paper. Paper presented at the OECD Japan Seminar. 2002

[14] B. Collis and I.S. Jung. Uses of information and communication technologies in teacher education. In B. Robinson and C. Latchem(eds), teacher education through open and distance learning. RoutledgeFalmer. 2003

[15] A.C.A. Ten Brummelhuis. Models of educational change: the introduction of computers in Dutch Secondary educaton. Enschede, University of Twente. 1995

[16] N.B. Strudler and K. Wetzel. Lessons from exemplary colleges of education: factors affecting technology integration in pre-service programs. Educational technology research and development. 1999

[17] R.E. Anderson and S.L Dexter. School technology leadership: incidence and impact. Center for research on information technology and organization, university of California, Irvine. 2000.

[18] Bangkok. Integrating ICT into School Curricula; Workshop in Bangkok. (2004)

[19] L. Flanangan \& M. Jacobsen. Technology Leadership for theTwenty-first Century Principal', Journal of Educational Administration, 41:2,124-142. 2003

[20] M. Drent and M. Meelissen. Which Factors Obstruct or Stimulate Teacher Educators to Use ICT Innovatively? Journal of Computers \& Education.2007.

[21]. D. Butler \& M. Sellbom. Barriers to Adopting Technology for Teaching and Learning. Educase Quarterly. 25(2), 22-28 